\title{
ÓLEOS ESSENCIAIS DE PLANTAS MEDICINAIS E AROMÁTICAS NO CONTROLE DO CARRAPATO RHIPICEPHALUS MICROPLUS
}

\author{
ESSENTIAL OILS OF MEDICINAL AND AROMATIC PLANTS IN THE CONTROL OF TICK \\ RHIPICEPHALUS MICROPLUS
}

\author{
Campos, R.N.S. ${ }^{1 *}$, Bacci, L. ${ }^{1}$, Araújo, A.P.A. ${ }^{2}$, Blank, A.F. ${ }^{1}$, Arrigoni-Blank, M.F. ${ }^{1}$, \\ Santos, G.R.A. ${ }^{1}$ e Roner, M.N.B. ${ }^{1}$
}

\begin{abstract}
'Universidade Federal de Sergipe (UFS). Centro de Ciências Biológicas e da Saúde. Departamento de Engenharia Agronômica. São Cristóvão, SE. Brasil. *roseane_nunes@hotmail.com

${ }^{2}$ Departamento de Biologia. Universidade Federal da Bahia. Instituto Mutidisciplinar em Saúde. Vitoria da Conquista, BA. Brasil.
\end{abstract}

PaLAVRAS CHAVE ADICIONAIS

Controle alternativo. Ectoparasitas. Bovinos.

\section{RESUMO}

O carrapato bovino Riphicephalus microplus (Acari: Ixodidae) constitui um dos grandes problemas enfrentado pelos pecuaristas de várias partes do mundo. No Brasil este ectoparasita causa grandes prejuízos à bovinocultura devido ao processo de hematofagia e pela transmissão de agentes patogênicos nos animais hospedeiros. Diante dessa situação os produtores normalmente aplicam carrapaticidas organossintéticos de forma indiscriminada. Este método normalmente resulta em: intoxicação dos animais e dos aplicadores, resíduos de carrapaticidas nos produtos de origem animal, resistência dos carrapatos aos carrapaticidas químicos e poluição ambiental. Uma alternativa para diminuir esses problemas é uso de biocarrapaticidas de origem botânica. Os pesticidas botânicos são produtos naturais derivados do metabolismo secundário das plantas. Esse metabolismo produz uma grande diversidade de compostos com ação carrapaticida que podem ser explorados através do uso de óleos essenciais ou como modelo para síntese de pesticidas sintéticos. A necessidade de métodos mais seguros, menos agressivos ao homem e ao meio ambiente, tem estimulado a busca de novos carrapaticidas a partir de produtos vegetais. Assim, acredita-se que o uso de óleos essenciais de plantas medicinais e aromáticas de uma forma isolada ou associada pode reduzir: a velocidade do desenvolvimento da resistência dos carrapatos aos carrapaticidas, os resíduos

\section{AdDitionAL KEYWORDS}

Alternative control. Ectoparasites. Cattle.

nos produtos de origem animal e a toxicidade para os animais, aplicadores e meio ambiente.

\section{SUMMARY}

The Riphicephalus microplus cattle tick (Acari: Ixodidae) is one of the major problems faced by farmers in various parts of the world. In Brazil this ectoparasite causes great damage to cattle due to the process of blood feeding and the transmission of pathogens in animal hosts. Given this situation, the producers usually apply organic synthetic acaricides indiscriminately. This method usually results in: poisoning of animals and applicators, acaricide residues in products of animal origin, resistance of ticks to chemical acaricides and environmental pollution. An alternative to reduce these problems is to use products of botanical origin. The botanical pesticides are natural products derived from secondary metabolism of plants. This metabolism produces a wide variety of compounds with anti-ticks action that can be exploited through the use of essential oils or as a model for synthesis of pesticides. The need for methods more secure and less aggressive to humans and the environment, has stimulated the search for new products from plants. Thus, it is believed that the use of essential oils from medicinal and aromatic plants alone or in combination, can reduce: the speed of development resistance of ticks to acaricides, presence of residues in products of 
animal origin, and toxicity to animals, applicators and the environment.

\section{INTRODUÇÃO}

O carrapato bovino Rhipicephalus microplus (Acari: Ixodidae) é sem dúvida uma das pragas zootécnicas mais importantes para a pecuária brasileira. Em muitos casos este ectoparasita compromete a produção de carne e leite devido às injúrias provocadas nos animais. Durante a hematofagia, os carrapatos inoculam toxinas que promovem alterações fisiológicas nos animais infectados. Neste processo pode ainda ocorrer a transmissão de agentes infecciosos, principalmente Anaplasma sp. e Babesia sp., responsáveis pelo complexo Tristeza Parasitaria Bovina(TPB). $\mathrm{O}$ carrapato bovino pode ainda reduzir a qualidade do couro do animal devido às cicatrizes ocasionadas na pele do hospedeiro durante a sua alimentação.

Várias pesquisas relacionadas ao controle de $R$. microplus estão sendo desenvolvidas, tais como: o desenvolvimento de vacinas, rotação de pastagens, cruzamentos com raças bovinas resistentes, controle biológico com alguns tipos de fungos e uso de homeopatia e extratos vegetais. Contudo, a maior parte dos pecuaristas utiliza ou tem acesso, apenas a produtos químicos para fazer o controle desse ectoparasita. Aplicações constantes de pesticidas sintéticos e o descarte indiscriminado da solução residual de carrapaticida têm sido responsáveis pelo aumento da resistência dos carrapatos aos pesticidas utilizados, intoxicação dos animais e dos aplicadores, resíduos de carrapaticidas nos produtos de origem animal e contaminação de solos e águas. Diante deste contexto, existe a necessidade imediata de uma alternativa aos produtos organossintéticos utilizados atualmente.

A utilização de plantas medicinais e aromáticas no controle de carrapatos tem sido foco de pesquisas em vários países. Os - óleos essenciais destas plantas são amplamente utilizados nas indústrias alimentares e de cosméticos. Possuem atividade terapêutica, bactericida, fungicida e inseticida e, recentemente também está sendo testada sua atividade carrapaticida. Os óleos essenciais são misturas complexas de compostos orgânicos voláteis de baixo peso molecular formados principalmente por monoterpenos, sesquiterpenos e fenilpropanóides. Algumas vezes o efeito carrapaticida é atribuído aos constituintes isolados em maior quantidade no óleo essencial que são os componentes majoritários. Porém, é possível que a atividade do componente principal seja modulada por outros compostos que estão em menor quantidade.

Dessa forma, a utilização de óleos essenciais de plantas medicinais e aromáticas no controle de R. microplus pode atenuar os problemas causados por esse ectoparasita, reduzindo assim a utilização de produtos organossintéticos que são tóxicos para o animal, homem e meio ambiente. Além disso, os óleos essenciais poderão funcionar como fontes de moléculas para a síntese de novos carrapaticidas, diminuindo a dependência dos pecuaristas aos produtos organossintéticos existentes no mercado.

\section{RHIPICEPHALUSMICROPLUS}

O carrapato bovino R. microplus é a única espécie do subgênero Boophilus que ocorre no Brasil. São carrapatos da família Ixodidae, conhecida como família dos carrapatos duros. Pertencem à ordem Parasitiformes da classe Arachnida e da subordem Metastigmata ou Ixodides. O ciclo de vida destes carrapatos consiste em: ovo, larva, ninfa e adulto (Fletchman, 1990; Rey, 2001).

Nesta família o dimorfismo sexual é acentuado. Os machos apresentam um escudo que recobre todo o dorso do animal e nas fêmeas, larvas e ninfas o escudo dorsal não vai além do propodossoma, região do corpo 
que vai do primeiro ao segundo par de pernas (Fletchman, 1990; Sonenshine et al., 2002).

Em todas as fases pós-embrionárias $R$. microplus se alimenta de sangue de mamíferos, aves, répteis e anfíbios (Rey, 2001), sendo que as larvas se alimentam preferencialmente de plasma (Pereira et al., 2008). O carrapato bovino é monóxeno, isto é, necessita de apenas um hospedeiro para completar o ciclo de vida que pode ser dividido em fase parasitária e fase nãoparasitária (Furlong, 2005). A fase parasitária tem início com a fixação das larvas no hospedeiro suscetível e termina quando os adultos, incluindo as fêmeas fecundadas e ingurgitadas caem do hospedeiro. A fase não parasitária começa com a teleógina (fêmea ingurgitada) depois que se desprende do hospedeiro e cai no solo para realizar a oviposição. Essa fase termina quando as larvas eclodem dos ovos e acessam o hospedeiro suscetível(Pereira, 1982; Pereira et al., 2008).

A fêmea pode colocar de 2000 a 4000 ovos. As larvas recém-nascidas necessitam de três a quatro dias para que se formem as peças bucais e então possam procuram e se fixar no couro dos animais hospedeiros. Normalmente são muito vivazes e sobem rapidamente nas folhas e hastes do pasto aguardando a passagem de um hospedeiro para se fixarem, preferencialmente onde a pele é mais fina, como: nas axilas, entre as patas, região genital e sob a cauda. Para fixarem ao hospedeiro as peças bucais dos carrapatos ficam envoltas em material não celular produzido pelas glândulas salivares, denominado de cemento. O esforço necessário para retirada destes ectoparasitas fixados a epiderme sugere que o cemento encontra-se firmemente ligado a esta (Pereira et al., 2008). As glândulas salivares desempenham um importante papel na alimentação dos carrapatos, pois produzem substancias anticoagulantes, enzimas hidrolíticas e proteolíticas (Kaumfan, 1976; Recke Junior et al., 2009). Assim, o início e o término do ciclo acontecem quase sempre no pasto, onde geralmente interagem o ectoparasita, o hospedeiro e o ambiente (Pereira, 1982; Pereira et al., 2008).

Rhipicephalus microplus parasita preferencialmente o boi, mas pode esporadicamente parasitar outros animais (Gonzales, 1975; Fletchman, 1990). Porém para Pereira et al. (2008), em outros animais domésticos como eqüinos, ovinos e caprinos, poucos carrapatos atingem o estádio de fêmea ingurgitada devido a um conjunto de fenômenos imunitários que acarretam grande mortalidade dos carrapatos principalmente no estádio larval.

Os prejuízos econômicos causados por $R$. microplus ocorrem de forma direta por efeito da picada e suas conseqüências, tais como: irritabilidade, perda de sangue e veiculação de patógenos; e de forma indireta como: o elevado custo do controle químico, os resíduos deixados nos produtos de origem animal e os danos ambientais decorrentes do uso desses produtos (Sonenshine et al., 2002). Devido a importância econômica o R.microplus representa um dos principais ectoparasitas dos bovinos (Alzate et al., 2008).

O carrapato bovino é o principal vetor de dois parasitos, a rickettsia Anaplasma sp. e o protozoário Babesia sp., responsáveis pelo complexo conhecido como TPB. Esta enfermidade é responsável por importantes prejuízos ao sistema de produção bovina (Gonzales, 1975; Furlong, 2005; Pereira et al., 2008). Estas hemoparasitoses bovinas causam anemia, diminuição no ganho de peso, redução na produção de leite e podem, em casos mais graves levar os animais a morte (Kocan, 2003). Bovinos da subespécie Bos taurus indicus (raças indianas) são menos suscetíveis a infestação por $R$. microplus quando comparados a subespécie Bos taurus taurus (raças européias) e consequentemente adquirem menos hemoparasitoses (Constatinoiu et al., 2010). Benavides e Sacco (2007) relataram que existem animais da subespécie Bos taurus 
taurus que são mais resistentes a babesiose quando comparados a outros bovinos da mesma subespécie, sendo que estes quando adquiriam a doença não apresentavam nenhum sinal clínico e os suscetíveis tiveram a necessidade de receber tratamentos para evitar a morte.

O parasitismo pelo carrapato Rhipicephalus (Boophilus) microplus em países tropicais e subtropicais é associado a grandes quedas nos índices de produtividade dos rebanhos. O controle convencional deste ectoparasita vem demonstrando ineficácia como estratégia de controle em longo prazo, além disso, existem relatos recorrentes de populações de carrapatos resistentes às formulações comercialmente disponíveis (Biegelmeyer et al., 2012).

Entre os ectoparasitas de bovinos, a infestação por $R$. microplus continua a ser uma das principais causas de perda econômicas da pecuária brasileira (Graf et al., 2004; Reck Júnior et al., 2009).

\section{CARRAPATICIDAS ORGANOSSINTÉTICOS}

Devido aos prejuízos econômicos causados por carrapatos à pecuária brasileira, os produtores têm utilizado intensivamente o controle químico para combatê-los (Kaufman, 2010). Atualmente, o uso de pesticidas sintéticos para o controle de artrópodes levanta várias preocupações relacionadas ao meio ambiente e a saúde humana (Nerio, 2010). O uso de carrapaticidas em bovinos causa grande impacto ambiental (Ching-Jones, 2008). Nesse contexto, pode ser citada como exemplo a contaminação de solos e águas por pesticidas empregados no controle de carrapatos em bovinos. Habitualmente centenas de litros de solução residual de carrapaticida são gerados e muitas vezes descartados indiscriminadamente pelo produtor rural (Marthe et al., 2010). Os piretróides correspondem a aproximadamente um terço de todos pesticidas utilizados no mundo e também estão entre os carrapaticidas mais vendidos. A permanência dos piretróides deltametrina, cipermetrina e permetrina na água e no solo úmido protegido da incidência direta da luz solar pode chegar até 80 dias (Vieira et al, 2007). O acúmulo de carrapaticidas no solo reduz consideravelmente a matéria orgânica presente neste, com isso prejudicando o solo (ChingJones, 2008).

Para Chagas et al. (2004), os carrapaticidas e seus metabólitos são considerados tóxicos a qualquer animal, inclusive ao homem, havendo ainda possibilidade de contaminação dos produtos de origem animal. A qualidade do leite pode ser prejudicada pela presença de carrapaticidas, pois a utilização indiscriminada dessas substâncias pode contaminar este produto e seus derivados com resíduos acima do limite máximo de resíduos (LMR) permitido pela legislação brasileira (Marthe et al., 2010). Os resíduos de avermectinas no leite têm sido avaliados dentro do programa de monitoramento do Ministério da Agricultura, Pecuária e Abastecimento. Resultados desse programa identificaram em 2008 a presença de cerca de $5 \%$ de amostras de leite com resíduos de ivermectina variando de 22 a $60 \mu \mathrm{g} / \mathrm{mL}$, acima do LMR que para este produto é de $10 \mu \mathrm{g} / \mathrm{mL}$ (Bastos et al., 2011).

Além da contaminação ambiental e dos resíduos nos produtos animais e seus derivados, a utilização dos carrapaticidas organossintéticos têm favorecido o desenvolvimento da resistência dos carrapatos a estes produtos. O controle convencional de parasitas baseado na utilização de carrapaticidas, há anos vem demonstrando sua ineficácia como estratégia de controle a longo prazo, através de recorrentes relatos de populações de ectoparasitas resistentes às formulações comercialmente disponíveis (Biegelmeyer et al., 2012). No Brasil, a resistência das populações de carrapatos aos carrapaticidas é generalizada (Graf et al., 2004). Há relatos 
de resistência de populações deste ectoparasito a maior parte dos pesticidas sintéticos usados no Brasil (Klafke et al., 2006; Mendes et al., 2011). Em alguns casos, $R$. microplus apresenta resistência antes de entrar em contato com determinado produto. Isso ocorre porque já existiam alguns indivíduos naturalmente resistentes, ou então, como é mais comum, o uso freqüente do produto causou alterações (mutações) em alguns indivíduos da população tornando-os menos suscetível. É o chamado estabelecimento do alelo resistente. A continuidade do uso desse produto faz aumentar o número de indivíduos com essa característica de resistência. Isso ocorre, uma vez que morre a maioria dos indivíduos sensíveis e os resistentes acasalam entre si, produzindo descendentes cada vez mais resistentes e em maior número na população. A predominância do alelo resistente ou o aparecimento da resistência é o momento em que a maior parte da população descende de carrapatos resistentes. Estes carregam, em maior ou menor porcentagem, os genes responsáveis pelas alterações fisiológicas, bioquímicas ou comportamentais, capazes de fazer a população sobreviver aos acaricidas empregados em seu controle (Furlong, 2000).

O uso incorreto de carrapaticidas (subdoses, superdoses, preparos inadequados, aplicações mal realizadas, excesso de aplicações, etc.) faz com que os indivíduos resistentes sejam selecionados. Cada vez que os carrapatos sobrevivem a uma aplicação de carrapaticida eles transmitem às gerações posteriores informações genéticas de como sobreviver àquele produto (Furlong, 2005; Pereira et al., 2008). As principais características da resistência apresentadas pelos carrapatos são genéticas e de caráter irreversível, ou seja, filhos de pais resistentes também serão resistentes. A suspensão do uso de um produto por um determinado período de tempo para uma população que tenha exibido resistência não o habilitará a um novo uso
eficaz(Gonzáles, 1975).

Castro Janer et al. (2011), verificaram no Uruguai que $R$. microplus é resistente a carrapaticidas organofosforados e piretróides e, recentemente foi descoberto resistência de algumas populações deste ectoparasita a fipronil e ivermectina. Segundo Klafke et al. (2006), resistência a ivermectina em populações de campo de $R$. microplus tem sido observada no Brasil desde 2001. Em um estudo feito no estado de São Paulo foi encontrado larvas de carrapatos $R$. microplus resistentes a cipermetrina e a deltametrina (Mendes et al., 2011).

O desenvolvimento da resistência é uma séria preocupação devido à falta de novas moléculas para controlar $R$. microplus. Como a abordagem tradicional de controle de carrapatos não está sendo muito bem sucedida, novas estratégicas e buscas alternativas são necessárias para o manejo destes artrópodes.

\section{PLANTAS COM ATIVIDADE CARRAPATICIDA}

Apesar de o Brasil possuir muitas espécies vegetais e ser considerado o país com o maior número de espécies no mundo, estudos sobre os possíveis efeitos terapêuticos dessas plantas são escassos (Di stasi e Hiruma-Lima, 2002).

A utilização de biocarrapaticidas oriundos do metabolismo secundário das plantas apresenta inúmeras vantagens quando comparado ao emprego de produtos organossintéticos. Dentre estas podemos citar: i) são obtidos a partir de recursos renováveis, ii) são rapidamente degradáveis, iii) o desenvolvimento da resistência a essas substâncias compostas da associação de vários princípios ativos é um processo lento, iv) não deixam resíduos nos alimentos e, v) são de fácil acesso e obtenção (Roel, 2001).

O metabolismo secundário das plantas possui grande diversidade de compostos 
com ação pesticida que podem ser explorados através de extratos vegetais. Os pesticidas botânicos normalmente apresentam baixo custo, diminuem o impacto ambiental e são de pequena toxicidade ao homem e a organismos não-alvo (Moreira et al., 2007; Bagavan et al., 2009). O metabolismo secundário de plantas pode variar consideravelmente dependendo de vários fatores, como: sazonalidade, índice pluviométrico, radiação $U V$, composição atmosférica $\left(\mathrm{CO}_{2}\right.$, $\mathrm{SO}_{2}, \mathrm{NO}_{2}$ e $\mathrm{O}_{2}$ ), herbivoria e ataque de patógenos, temperatura, ritmo circadiano, etc. Estes fatores provocam variações fisiológicas no desenvolvimento dos órgãos, alterações morfológicas nas flores e folhas e modificações nas estruturas secretoras (Sepúlveda-Jimenez et al., 2003; Figueiredo, 2008). Métodos mais apurados de pesquisa, de separação e quantificação de princípios ativos estão conseguindo encontrar e medir com sucesso essas substâncias presentes em plantas (Taylor et al., 2001).

As plantas com atividade pesticidas podem causar diversos efeitos sobre os artrópodes, como repelência, inibição de oviposição e da alimentação, causar distúrbios no desenvolvimento, deformações, infertilidade e mortalidade nas diversas fases. A extensão dos efeitos e o tempo de ação são dependentes da dosagem utilizada. A utilização de doses subletais pode causar redução das populações a longo prazo (Roel, 2001).

As espécies botânicas mais usadas como plantas pesticidas pertencem às famílias Meliaceae, Rutaceae, Asteraceae, Annonaceae, Lamiaceae e Canellaceae (Jacobson, 1989). Atualmente, com relação à atividade carrapaticida, várias espécies estão sendo pesquisadas, tais como: Azadirachta indica (Martinez, 2002); Cymbopogon nardu (Olivo et al., 2008), Lavandula angustifolia (Pirali-Kheirabadi e Silva, 2010), Tetradenia riparia (Gazim et al., 2011), Petiveria alliacea (RosadoAguilar et al., 2010), Piper aduncum (Silva et al., 2009), Eucalyptus citriodora (Chagas et al., 2002), Ocimum basilicum (MartinezVelasques et al., 2011), Calea serrata (Ribeiro et al., 2011), Nicotiana tabacum (Rodriguez et al., 2010) entre outras. Assim, estas plantas poderão ser utilizadas posteriormente em programas de controle, na tentativa de reduzir a utilização de carrapaticidas organossintéticos.

O emprego de plantas com atividade inseticida e carrapaticida favorece especialmente o pequeno produtor, pelo menor custo, facilidade de utilização, não exigindo pessoal qualificado, e pelo fato de não afetar o meio ambiente. Além disso, as plantas podem ser cultivadas nas propriedades facilitando a utilização (Mazzoneto e Vendramin, 2003).

A utilização dos pesticidas botânicos pode ser dividida de acordo com a forma do preparo em: produto in natura, pó, extração aquosa ou alcoólica, óleos essenciais, formulações concentradas comerciais e semi-comerciais, purificação e isolamento dos compostos puros obtidos de extratos de plantas (Moreira et al., 2004).

Atividade acaricida de cinco plantas como: Brugmasia arborea, Sambucus nigra, Nicotiana tabacum, Bidens pilosa e Ambrosia cumanenses foi testada na forma de extrato puro e diluições e percebeu-se que a medida que o extrato puro era diluído a mortalidade das fêmeas do carrapato bovino $R$. microplus diminuía, possivelmente devido a relação dose resposta em que a maior concentração de compostos puros causam mais efeito carrapaticida (Rodriguez et al., 2010).

Assim a toxicidade de uma planta contra artrópodes não a qualifica necessariamente como um pesticida. Vários aspectos devem ser levados em consideração, tais como: forma de extração e conservação dos extratos, eficácia em baixas concentrações, ausência de toxicidade para mamíferos e animais superiores, fácil obtenção, manipulação e aplicação e viabilidade econômica (Viegas Junior, 2003). 


\section{ÓLEOSESSENCIAISNOCONTROLE DO RHIPICEPHALUSMICROPLUS}

Desde a Idade Média, os óleos essenciais têm sido usados como bactericidas, fungicidas, inseticidas e antiparasitários. Recentemente estes compostos têm sido empregados nas indústrias farmacêuticas, alimentares, agrícolas e de cosméticos (Bakkali et al., 2008). Óleos essenciais são oriundos do metabolismo secundário de plantas aromáticas. Caracterizam-se por misturas complexas de compostos orgânicos voláteis de baixo peso molecular formados principalmente por monoterpenos, sesquiterpenos e fenilpropanóides. Podem constituir ainda os óleos essenciais os álcoois, ésteres, éteres, aldeídos, cetonas, lactonas, fenóis e éteres de fenol (Bizzo e Rezende, 2009).

Os óleos essenciais são misturas muito complexas e podem conter cerca de 2-60 componentes em concentrações muito diferentes. Eles são caracterizados por dois ou três grandes componentes em concentrações bastante elevado (20-70\%) em comparação com os outros componentes presentes em quantidades vestigiais (Bakkali et al., 2008). Geralmente os componentes principais determinam as propriedades biológicas do óleo essencial (Pichersky et al., 2006). Porém para Mendes et al. (2010), os componentes majoritários que são isolados em maior quantidade nos óleos essenciais podem refletir as características biofísicas e biológicas destes, mas na maioria das vezes a amplitude dos efeitos dos óleos essenciais depende da concentração dos componentes principais modulada por outros componentes de menor importância, ou seja, os constituintes agindo em sinergia. Para uma mesma espécie de planta, o número de compostos, suas quantidades relativas e o rendimento de óleos essenciais variam consideravelmente, isto pode ser atribuído ao método de extração do óleo essencial, além das diferenças climáticas, localização e tempo de colheita (Bakkali et al., 2008).

Óleos essenciais pertecentes a várias espécies de plantas têm sido extensivamente testados para avaliar as suas propriedades como um valioso recurso natural no controle de carrapatos (tabela I). O óleo essencial de Copaifera reticulata, a árvore de copaíba, apresenta atividade carrapaticida sobre larvas de $R$. microplus (Fernandes et al., 2007). Segundo Gazim et al. (2011), a planta Tetradenia riparia (Lamiaceae) apresenta alta atividade carrapaticida sobre R. microplus. Estes autores observaram alta mortalidade de fêmeas ingurgitadas em baixas concentrações do óleo essencial desta planta, redução do número e peso de ovos, diminuição de eclosão de larvas e mortalidade de larvas (Gazim et al., 2011). Silva et al. (2009) testaram a toxicidade da espécie Piper aduncum (Piperaceae) proveniente da floresta amazônica em fêmeas ingurgitadas e larvas de $R$. microplus e demonstraram que a mortalidade das larvas desta espécie foi devida a um constituinte do óleo, derivado de um fenilpropanóide. Para Cardona et al., 2007 o uso de óleo essencial de Sapindus saponaria (Sapindaceae) é uma ferramenta promissora para o controle de carrapatos em bovinos, pois causam mortalidade nas fêmeas ingurgitadas e reduzem a eficiência reprodutiva destas. Broglio-Micheletti et al., 2009 observaram que o óleo extraído das sementes de Annona muricata foi eficaz em baixas concentrações no controle do carrapato bovino in vitro.

A atividade carrapaticida de citronela foi comprovada por Olivo et al. (2008), que verificaram que esta ação deve-se aos princípios ativos citronelal e geraniol. Chagas et al. (2002), realizaram um estudo em relação a atividade carrapaticida do Eucalyptus citriodora, E. globulus e E. staigeriana sobre o R. microplus. Os óleos essenciais das três espécies e os concentrados emulsionáveis de E. globulus e $E$. staigeriana foram testados em cinco concentrações diferentes contra larvas e 


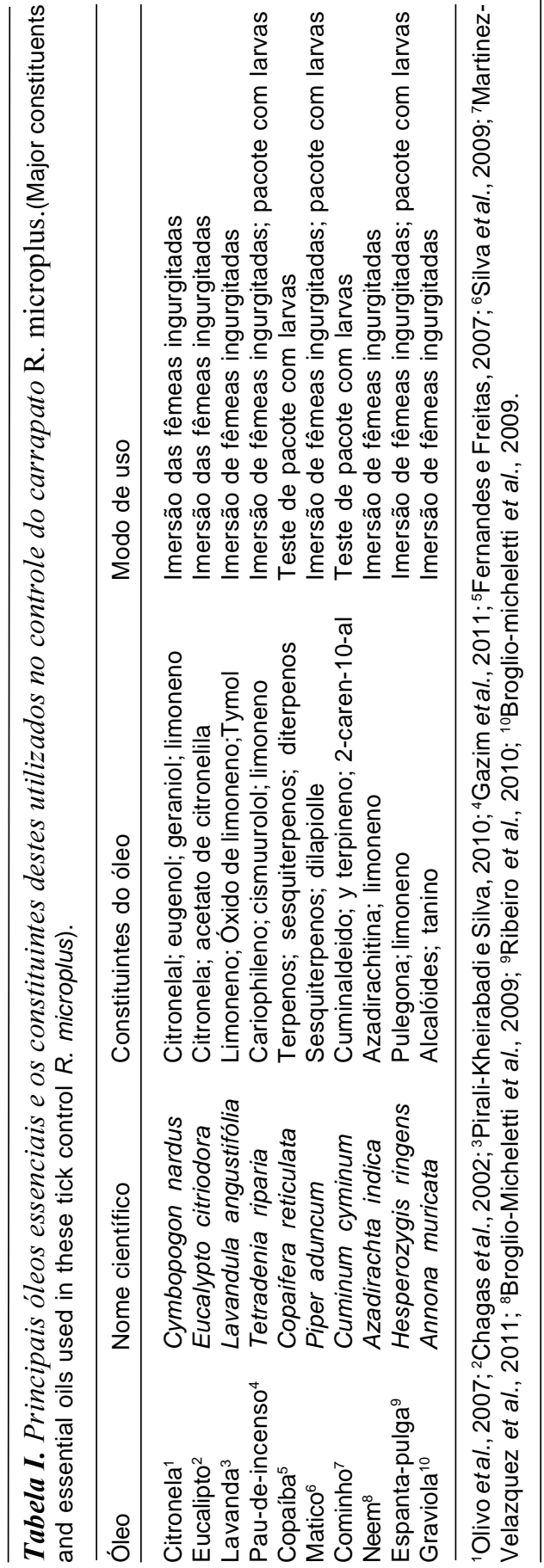

fêmeas ingurgitadas de $R$. microplus, foram submetidos à análise por cromatografia gasosa acoplada à espectrometria de massas (CG/EM), a fim de se investigar sua composição. Foi encontrado o citronelal como o principal componente do óleo essencial de E. citriodora, sendo este responsável pela ação carrapaticida. $\mathrm{O}$ mesmo ocorreu com o 1,8-cineol em $E$. globulus, sendo que em E. staigeriana foi demonstrado que várias substâncias agiam sinergicamente contra $R$. microplus. A mortalidade causada pelos óleos essenciais das espécies de Eucalyptus em larvas e fêmeas de $R$. microplus já era esperada, em função da presença de substâncias de comprovado efeito carrapaticida nos mesmos.

Segundo Romero 2008, os terpenos e seus derivados, como os monoterpenos e sesquiterpenos são substâncias encontradas comumente nos óleos essenciais e em conjunto com os fenilpropanóides formam inseticidas naturais potentes como os piretróides.

Na maioria das vezes os componentes principais que estão em maior quantidade nos óleos essenciais são testados comprovando que o efeito causado pelo óleo é devido a este composto majoritário, porém em alguns óleos essenciais alguns componentes agem em sinergismo (Leyva et al., 2009).

Apresentam importante efeito antiparasitário os óleos essenciais que apresentam compostos como timol; carvacol; geraniol; citronelal e linalol (Romero, 2008).

No processo de extração de óleo essencial podem ser aplicados diversos métodos, como a hidrodestilação, maceração, extração por solvente, enfleuragem, gases supercríticos e microondas. Dentre esses, o método de maior aplicação é o de hidrodestilação (Bakkali et al., 2008). Segundo Martin et al. (2011) o óleo essencial de Artemisia sp. quando extraído através de fluído super crítico demonstrou melhor rendimento e aumentou a quantidade dos 
constituintes em comparação com à extração por técnicas tradicionais. Além disso, extratos supercríticos foram pesticidas mais ativos do que os óleos extraidos por solvente orgânico e hidrodestilação. Porém uma desvantagem desse método é o alto custo.

A maioria dos óleos essenciais comercializados são analisados por cromatografia gasosa e espectometria em massa (Bakkali et al., 2008). Cada componente é identificado por meio da comparação de seu espectro de massas com espectros avaliados pelo banco de dados de um equipamento, com espectros existentes na literatura e comparação dos índices de retenção calculados com os que já existem na literatura (Adams, 2007).

Para Bueno (2005), o uso de produtos naturais deve ser incentivado, mas antes devem ser submetidos a todos os procedimentos de segurança da mesma forma que os produtos sintéticos. Em um estudo do óleo essencial de Heperozygis ringen (Lamiaceae) encontrada na região sul do Brasil foi observada atividade carrapaticida nesta espécie, porém um dos constituintes desse óleo esssencial, a pulegona tem sido associada a hepatotoxicidade e morte de mamíferos (Ribeiro et al., 2010).

\section{CONSIDERAÇÕESFINAIS}

A necessidade de métodos mais seguros, menos agressivos ao homem e ao meio ambiente tem estimulado a busca de novos pesticidas a partir de extratos vegetais. $\mathrm{O}$ controle de ectoparasitas nos bovinos

\section{BIBLIOGRAFIA}

Adams, R.P. 2007. Identification of essential oil components by gas chromatography/ mass spectroscopy. Allured. Carol Stream IL, USA, $807 \mathrm{pp}$.

Alzate, C.B., Gutiérrez, I.G. y Saldarriaga, Y.O. 2008. Patogenicidad de Lecanicillium lecanii (Fungi) sobre la garrapata Boophilus microplus (Acari: Ixodidae) en laboratorio. Rev Colombiana Entomol, 34: 90-97. através de produtos químicos convencionais, além dos problemas de resíduos nos alimentos, contaminação ambiental e intoxicação de aplicadores, encontra ainda o entrave do desenvolvimento acelerado da resistência dos carrapatos aos produtos. $\mathrm{O}$ uso inadequado e exagerado desses produtos acentua estes problemas tornando o manejo de carrapatos no Brasil uma prática onerosa, ineficiente e prejudicial à saúde humana e ao meio ambiente.

Os biocarrapaticidas obtidos através de espécies vegetais permitirão a redução da utilização dos carrapaticidas organossintéticos no controle de $R$. microplus e com isso espera-se mitigar os problemas econômicos, sociais, ecológicos e ambientais advindos da utilização destes produtos. A utilização dos óleos essenciais de plantas medicinais e aromáticas no controle de $R$. microplus deverá, além de reduzir o custo de controle, diminuir: i) a presença de resíduos nos produtos obtidos a partir dos animais (carne e leite), ii) a intoxicação de aplicadores, iii) a toxicidade a organismos não alvos, iv) a resistência dos carrapatos aos carrapaticidas e, v) a contaminação da água/solo.

Contudo, apesar das vantagens da utilização de biocarrapaticidas em relação aos carrapaticidas convencionais, é preciso que se desenvolvam mais pesquisas para comprovar a eficiência destes novos produtos sobre os carrapatos e se esclareçam os reais efeitos destes sobre os organismos não-alvo e ao meio ambiente.

Bagavan, A., Kamaraj, C., Elango, G., Zahir, A.A. and Rahuman, A.A. 2009. Adulticidal and larvicidal efficacy of some medicinal plant extracts against tick, fluke and mosquitoes. Vet Parasitol, 166: 286-292.

Bakkali, F., Averbeck, S., Averbeck, D. and Idaomar, M. 2008. Biological effects of essential oils. A review. Food Chem Toxicol, 26: 446-475.

Bastos, L.H.P., Cardoso, M.H.W.M., Nóbrega, A.W. 
and Jacob, S.C. 2011.Possible contamination sources of milk by agrotoxics and studies on monitoring their residues: a Brazilian national review. Caderno Saúde Col, 19: 51-60.

Benavides, M.V and Sacco, A.M.S. 2007. Differential Bos taurus cattle response to Babesia bovis infection. Vet Parasitol, 150: 54-64.

Biegelmeyer,P., Nizoli, L.Q., Cardos, F.F. e Dionello, N.J.L. 2012. Aspectos da resistência de bovinos a carrapatos Riphicephalus (boophilus) microplus. Arch Zootec, 61: 1-11.

Bizzo, H.R., Hovell, A.M.C. e Rezende, C.M. 2009. Óleos essenciais no Brasil: aspectos gerais, desenvolvimento e perspectivas. Quim Nova, 32: 588-594.

Broglio-Micheletti, S.M.F., Neves-Valente, E.C., Souza, L.A., Silva-Dias, N., Girón-Pérez, K. and Prédes-Trindade, R.C. 2009. Control de Rhipicephalus (Boophilus) microplus (Acari: Ixodidae) con extractos vegetales. Rev Colombiana Entomol, 135: 145-149.

Bueno, O.C. 2005. Plantas inseticidas no controle de formigas cortadeiras. Rev Agroecol Hoje, 28: 20-22.

Cardona, E.Z, Torres, F.R. y Echeverri, F.L. 2007. Evaluación in vitro de los extractos crudos de sapindus saponaria sobre hembras ingurgitadas de Boophilus microplus (Acari: Ixodidae), Scientia et Technica, 13: 51-54.

Castro Janer, E., Rifran, L., Gonzalez, P.,Niell, C.,Piaggio, J., Gil, A. and Schumaker, T.T.S. 2011.Determination of the susceptibility of Rhipicephalus (Boophilus) microplus (Acari: Ixodidae) to ivermectin and fipronil by larval immersion test (LIT) in Uruguay. Vet Parasitol, 178: $148-155$.

Chagas, A.C.S. 2004. Controle de parasitas utilizando extratos vegetais. Rev Bras Parasitol Vet, 13: 156-160.

Chagas, A.C.S., Passos, W.M., Prates, H.T., Furlong, J. e Leite, R.C. 2002. Efeito acaricida de oleos essencias e concentrados emulsionaveis de Eucalyptus spp em Boophilus microplus. Braz J Vet Res Anim Sci, 39: 247-253.

Ching-Jones, R.W. 2008. Residualidade de substancias xenobióticas en el suelo empleadas em la producción pecuária. Agron Mesoamer, 19: 99-114.

Constantinoiu, C.C., Jackson, L.A., Jorgensen,
A.E., Lew-Tabor, A.E., Piper, E.K. and Mayer, D.G. 2010. Local immune response against larvae of Rhipicephalus (Boophilus) microplus in Bos taurus indicus and Bos taurus taurus cattle. Int J Parasitol, 40: 865-875.

Di stasi, L.C. e Hiruma-Lima, C.A. 2002. Plantas medicinais na Amazônia e na Mata Atlântica. $2^{\mathrm{a}}$ ed. UNESP. São Paulo. Brasil. 160 pp.

Fernades, F.J., Jorge, I., Calvo, E.V.A., Alejjo, E., Carbu, M., Camafeita, E., Garrido, C., Lopez, J.A., Jorrin. J. and Cantoral, J.M. 2007. Proteomic analysis of phytopathogenic fungus Botrytis cinerea as a potential tool for identifying pathogenicity factors, therapeutic targets and for basic research. Arch Microbiol, 187: 207215.

Figueiredo, A.C., Barroso, J.G., Pedro, L.G. and Scheffer, J.J.C. 2008. Factors affecting secondary metabolite production in plants: volatile components and essential oils. Flavour Frag J, 23: 213-226.

Fletchmann, C.H.W. 1990. Ácaros de importância médico veterinária. $3^{a}$ ed. Editora Nobel. São Paulo. Brasil. 185 pp.

Furlong, J. 2000. Controle estratégico de endo e ectoparasitos em bovinos de leite na região do Brasil-Central. In: Bressan, M., Martins, C.E., Vilela, D. Sustentabilidade da pecuária de leite no Brasil. Embrapa Gado de Leite. Juiz de Fora. Minas Gerais. pp. 165-174.

Furlong, J. e Martins, J.R.S. 2005. Resistência dos carrapatos aos carrapaticidas. Embrapa Gado de Leite. Juiz de Fora, MG. pp. 7-17.

Gazim, Z.C., Demarchi, I.G., Lonardoni, M.V.C., Amorim, A.C.L., Hovell, A.M.C., Rezende, C.M., Ferreira, G.A., Lima, E.L., Cosmo, F.A. and Cortez, D.A.G. 2011. Acaricidal activity of the essential oil from Tetradenia riparia (Lamiaceae)on the cattle tick Rhipicephalus (Boophilus) microplus (Acari; Ixodidae). Exp Parasitol, 129: 175-180.

Gonzales, J.C. 1975. O controle do carrapato bovino. Editora Sulina. Porto Alegre. 104 pp.

Graf, J.F., Gogolewsk, N., Leach-Bing, G.A., Sabatini, M.B., Molento, E.L. and Arantes, G.J. 2004. Tick control: an industry point of view. Parasitology, 129: 427-442.

Jacobson, M. 1989. Botanical pesticides: past, present and future. In: Arnason, J.T.,Philogene, B.J.R., Morand, P. Inseticides of plant origin. 


\section{ÓLEOS ESSENCIAIS DE PLANTAS NO CONTROLE DO RHIPICEPHALUS MICROPLUS}

American Chemical Society. Washington. pp. $1-10$.

Kaufman, W.R. 1976. The influence of various factors on fluid secretion by in vitro salivary glands of ixodid ticks. J Exp Biol, 64: 727-742.

Kaufman, W.R. 1989. Tick-host interaction: a synthesis of currents concepts. Parasitol Today, 5: 47-56.

Kaufman, W.R. 2010. Ticks: Physiological aspects with implications for pathogen transmission. Ticks and Tick-borne Dis, 1: 11-22.

Klafke, G.M., Sabatini, G.A., Albuquerque, T.A.A., Martins, J.R., Kemp, D.H., Miller, R.J., and Schumaker, T.T.S. 2006. Larval immersion tests with ivermectin in populations of the cattle tick Rhipicephalus (Boophilus) microplus (Acari: Ixodidae) from the State of Sao Paulo, Brazil. Vet Parasitol, 142: 386-390.

Kocan, K.M., La Fuente, J., Guglielmonte, A.A. and Melendez, R.D. 2003. Antigens and alternatives for control of Anaplasma marginale infection in cattle. Clin Microbiol, 16: 698-712.

Leyva, M., Marquetti, M.C., Tacoronte, J.E., Scull, R., Tiomno, O., Mesa, A. y Montada, D. 2009. Actividad larvicida de aceites esenciales de plantas contra Aedes aegypti (L.) (Diptera: Culicidae). Rev Biomed, 20: 5-13.

Marthe, E.D.B., Bittencourte, L.M. e Queiroz, M.E.L.R. 2010. Desenvolvimento de metodologia para determinação de piretróides em manteiga. Quím Nova, 33: 1389-1393.

Martín, L., Julio, L.F., Burillo, J., Sanz, J., Mainar, A.M. and Gonzalez-Coloma, A. 2011. Comparative chemistry and insect antifeedant action of traditional (Clevenger and Soxhlet) and supercritical extracts $\left(\mathrm{CO}_{2}\right)$ of two cultivated wormwood (Artemisia absinthium L.) populations. Ind Crop and Prod, 34: 615- 621.

Martinez, S.S. 2002. O NIM - natureza, usos múltiplos e produção. Instituto Agronômico do Paraná-BR (IAPAR). Londrina. 142 pp.

Martinez-Velazquez, M., Castillo-Herrera,G.A., Rosario-Cruz, R., Flores-Fernandez, J.M., Lopez-Ramirez, J. and Hernandez-Gutierrez, R. 2011. Acaricidal effect and chemical composition of essential oils extracted from Cuminum cyminum, Pimenta dioica and Ocimum basilicum against the cattle tick Rhipicephalus (Boophilus) microplus (Acari: Ixodidae). Parasitol Res, 108: 481-487.
Mazzonetto, F. e Vendramim, J.D. 2003. Efeito de pós de origem vegetal sobre Acanthoscelides obtectus (Say) (Coleoptera: Bruchidae) em feijão armazenado. Neotrop Entomol, 32: 145149.

Mendes, S.S., Bonfim, R.R., Jesus, H.C.R., Alves, P.B., Blank, A.F., Estevam, C.S., Antoniolli, A.R, and Thomazi, S.M. 2010. Evaluation of the analgesic and anti-inflammatory effects of the essential oil of Lippia gracilis leaves, $J$ Ethnopharmacol, 129: 391-397.

Mendes, M.C., Lima, C.K., Nogueira, A.H., Yoshihara, E., Chiebao, D.P., Gabriel, F.H.L., Ueno, T.E.H., Namindome, A. and Klafke, G.M. 2011. Resistance to cypermethrin, deltamethrin and chlorpyriphos in populations of Rhipicephalus (Boophilus) microplus (Acari: Ixodidae) from small farms of the State of São Paulo, Brazil. Vet Parasitol, 178: 383-388.

Moreira, M.D., Picanço, M.C., Barbosa, L.C.A., Guedes, R.N.C. and Silva.M. da. 2004. Toxicity of leaf extracts of Ageratum conyzoides to Lepidoptera pests of horticultural crops. Biol Agric Hort, 22: 251-260.

Moreira, M.D., Picanço, M.C., Martins, J.C., Campos, M.R. e Chediak, M. 2007. Uso de inseticidas botânicos no controle de pragas. In: Zambolin, L., Lopes, C.A., Picanço, M.C., Costa, H. Manejo integrado de doenças e pragas. Suprema Gráfica e Editora. Visconde do Rio Branco. Brasil. pp. 577-606.

Nerio, L.S., Olivero-Verbel, J. and Stashenko, E. 2010. Repellent activity of essential oils: A review. Bioresource Technol, 101: 372-378.

Olivo, C.J., Carvalho, N.M., Silva, J.H.S., Vogel, F.F, Massariol, P., Meinerz, V.G., Agnolin, C., Morel, A.F. e Viau, V.F.V. 2008. Óleo de citronela no controle do carrapato de bovinos. Ciên Rural, 38: 406-410.

Pereira, M.C.1982. Boophilus microplus - Revisão taxonômica e morfo-biológica. $1^{\text {a }}$ ed. Químio Divisão Veterinária. São Paulo. pp. 7-45.

Pereira, M.C., Labruna, M.B., Szabó, M.P e Klafke, G.M. 2008. Rhipicephalus (Boophilus) microplus. Biologia, Controle e Resistência. Editora MedVet. São Paulo. Brasil. 169 pp.

Pichersky, E., Noel, J.P. and Dudareeva, N. 2006. Biosynthesis of plant volatiles: nature's diversity and ingenuity. Science, 311: 808-811.

Pirali-Kheirabadi, K. and Silva, J.T. 2010. Lavandula 
angustifolia essential oil as a novel and promising natural candidate for tick (Rhipicephalus (Boophilus) annulatus) control. Exp Parasitol, 126: 184-186.

Reck Júnior, J, Berges, M., Terra, R.M.S., Marks, F.S., Vaz Júnior, I.S., Guimaraes, J.A. and Termignoni, C. 2009. Systemic alterations of bovine hemostasis due to Rhipicephalus (Boophilus) microplus infestation. Res Vet Sci, 86: 56-62.

Rey, L. 2001. Parasitologia. Editora Guanabra Koogan. Rio de Janeiro. Brasil. 349 pp.

Ribeiro, V.L.S., Santos, J.C., Bordignon, S.A.L., Apel, M.A., Henriques, A.T and Von Poser, G.L. 2010. Acaricidal properties of the essential oil from Hesperozygis ringens (Lamiaceae) on the cattle tick Riphicephalus (Boophilus) microplus. Bioresource Technol, 101: 2506-2509.

Ribeiro, V.L.S., Avancini. C., Gonçalves, K., Toigo, E. and Von-Poser, G. 2011. Acaricidal activity of Calea serrata (Asteraceae) on Boophilus microplus and Rhipicephalus sanguineus Vet Parasitol, 151: 351-354.

Rodriguez, A.S., Rodriguez, C.M. y Cruz, A.C. 2010. Efecto ixodicida de los extractos etanólicos de algunas plantas sobre garrapatas Rhipicephalus (Boophilus) microplus. Rev MVZ Córdoba, 15: 2175-2184.

Roel, A.R. 2001. Utilização de plantas com propriedades inseticidas: uma contribuição para o desenvolvimento rural sustentavel. Interações: Rev Int Desenvolv Local, 1: 43-50.

Romero, C.G. 2008. Fitoterapia em Ganaderia ecológica/orgânica flora medicinal de Espanã y Panamá. Editorial Agrícola Española. Madrid.
Espanã. 111 pp.

Rosado-Aguila, J.A., Aguilar-Caballero, A., RodriguezVivas, R.I., Borges-Argaez, R., Garcia-Vazquez, Z. and Mendez-Gonzalez, M. 2010. Acaricidal activity of extracts from Petiveria alliacea (Phytolaccaceae) against the cattle tick, Rhipicephalus (Boophilus) microplus (Acari: ixodidae). Vet Parasitol, 168: 299-303.

Sepúlveda-Jimenez, G., Porta-Ducoing, H. y RochaSosa, M. 2003. La participación de los metabolitos secundarios en la defensa de las plantas. Rev Méx Fitopatol, 21: 355-363.

Silva, W.C., Martins, J.R.S., Souza, E,M., Heizen, H., Cesio, M.V., Mato, M., Albetrecht, F., Azevedo, A.L. and Barros, N.M. 2009. Toxicity of Piper aduncum L. (Piperales: Piperaceae) from the Amazon forest for the cattle tick Rhipicephalus (Boophilus) microplus (Acari: Ixodidae). Vet Parasitol, 164: 267-274.

Sonenshine, D.E., Lane, R.S. and Nicholson, W.L. 2002. Ticks (Ixodida), In: Mullen, G. and L. Durden (Eds.). Medical Veterinary Entomology. Academic Press. San Diego. USA. pp. 517-558.

Taylor, J.L.S., Rabe, T., Mc Gaw, A.K., Jager, A.K. and Van Staden, J. 2001. Towards the scientific validation of traditional medicinal plants. Plant Growth Regul, 34: 23-37.

Viegas Junior, C. 2003. Terpenos com atividade inseticida: uma alternativa para o controle químico de insetos. Quím Nova, 26: 390-400.

Vieira, H.P., Neves, A.A., Lopes, M.E. e Queiroz, R. 2007. Otimização e validação da técnica de extração líquido-líquido com participação em baixa temperatura para piretróides em água e análise por cromatografia gasosa. Quim Nova, 30: 535-540. 